\title{
O uso de Fitoterápicos como auxílio no tratamento de Enfermidades do Trato Digestório
}

Eva Ivaldina Schaus Ribeiro ${ }^{1}$, Caroline Hass ${ }^{1}$, Janaina Cristina Iensen Gaspareto ${ }^{1}$, Thayliyza Zwierzykowski ${ }^{2}$; Thaliny Santos ${ }^{1}$, Caryna Eurich Mazur ${ }^{3}$

Resumo: O presente artigo visa discutir a importância da utilização de fitoterápicos para tratamento de doenças relacionadas ao trato digestório. Para tanto, utilizou-se de pesquisa bibliográfica para identificar quais plantas poderiam ser utilizadas com benefícios a esta região corpórea e averiguar em que medida poderiam apresentar toxicidade ao corpo humano. Neste momento, chegou-se ao número de sete plantas fitoterápicas, com seus benefícios elencados.

Palavras-chave: Fitoterápicos, plantas medicinais, doenças.

\section{The Herbal use in Disease in Treatment Digestive Tract}

\begin{abstract}
This paper discusses the importance of using herbal medicines to treat diseases related to the digestive tract. Therefore, we used bibliographical research to identify which plants could be used with benefits to this body region and ascertain to what extent could be toxic to the human body. At this time, it came to the number seven herbal plants with its listed benefits.
\end{abstract}

Keywords: Phytotherapy, medicinal plants, disease.

\section{Introdução}

Quando é abordada a importância das plantas para o Planeta Terra, comumente se enfoca principalmente a sua participação no ciclo do oxigênio, onde há conversão do gás carbônico em gás oxigênio, necessário para a respiração da maioria dos seres vivos. Entretanto, as plantas também podem ser utilizadas como fitoterápicos, na forma de chás, compressas, infusões, macerações, ingestão, banhos, por exemplo, em tratamentos medicinais e até hoje essa cultura é utilizada, sendo na sua maioria passada dos pais para os filhos.

\footnotetext{
${ }^{1}$ Nutricionista. Faculdade Campo Real. Guarapuava, Paraná, Brasil. E-mail: evaschaus@ hotmail.com; caroline.hass@hotmail.com; jana_cris@hotmail.com;

${ }^{2}$ Nutricionista. Pós-graduanda em Nutrição Clínica. Faculdade Campo Real. Guarapuava, Paraná, Brasil. thaylizazwier@ gmail.com;

${ }^{3}$ Nutricionista. Docente do curso de Nutrição. Faculdade Campo Real. Guarapuava, Paraná, Brasil.

E-mail: carynanutricionista@gmail.com
} 
Nesse sentido, um tema muito divulgado e comentado na atualidade é a qualidade de vida das pessoas, uma vez que o cotidiano da grande maioria leva ao estresse crônico e, consequentemente, à condução de enfermidades a ele relacionada.

A utilização de fitoterápicos é considerada como um método de tratamento que possibilita ao homem uma associação direta com o ambiente, acessando o poder da natureza, para ajudar o organismo a normalizar funções fisiológicas que sofreram algum estresse e acabaram sendo prejudicadas, restaurar a imunidade enfraquecida, promover a desintoxicação e o rejuvenescimento do corpo (PINTO et al., 2006).

Segundo dados da OMS no início da década de 1990 noticiou que 65-80\% da população dos países subdesenvolvidos dependiam das plantas medicinais como única forma de cuidados básicos de saúde. A valorização dessa ciência é de grande magnitude não só para a comunidade científica que necessita cada vez mais da confirmação dos destaques terapêuticos das ervas medicinais, mas também para o enriquecimento cultural de um povo, além de auxiliar para conservação dos recursos vegetais baseado em sua importância (MOREIRA et al., 2002).

Percebe-se uma crescente atenção das políticas governamentais para o uso de plantas medicinais, por diversos motivos e nos mais variados setores, por integrar o conhecimento popular ao avanço tecnológico e ao desenvolvimento sustentável na busca de uma política de assistência em saúde eficiente, abrangente e humanizada (OMS,1978).

O conhecimento tradicional (sabedoria popular) é definido "como o conjunto de saberes e saber-fazer a respeito do mundo natural e sobrenatural transmitido na boca a boca, de geração em geração". Esse conhecimento é transmitido a todos os na vida diária e não apenas no formal. A sua comunicação por meio da conversa é uma das diferenças que o separa do científico, que é transmitido por meio da escrita. Nesse sentido o conhecimento tradicional somente pode ser interpretado dentro do contexto cultural em que foi gerado (BRASIL, 2001).

Nesse sentido, o objetivo desse trabalho foi relacionar os fitoterápicos para tratamento de enfermidades do trato gastrintestinal. 


\section{Metodologia}

O estudo visou a escolha de artigos que abordassem os fitoterápicos que auxiliam nas funções do sistema gastrointestinal. Foram usados como base de dados, fonte primária e secundária de artigos científicos de bibliotecas virtuais, revisão de literatura bibliográfica e científica: SciELO e Google Acadêmico. Levando em consideração os benefícios e sua toxicidade de cada planta para os seres humanos e posologia indicada.

\section{Resultados e discussão}

Foram selecionados sete tipos de plantas medicinais para o tratamento especifico de desordens do trato gastrointestinal. No qual notou-se, após serem comparadas e analisadas certas características encontradas em algumas das plantas citadas no presente artigo (quadro $1)$.

Quadro 1 - Relação dos fitoterápicos indicados para desordens do sistema gastrintestinal

\begin{tabular}{|l|l|}
\hline Planta & \multicolumn{1}{|c|}{ Tratamento } \\
\hline Carqueja (Baccharis trimera) & $\begin{array}{l}\text { Ação antirreumática, estomáquica, anti-helmíntica, problemas } \\
\text { relacionados ao fígado além de ser considerada boa também para } \\
\text { gripe, debilidade física, anemia, anorexia, hanseníase. }\end{array}$ \\
\hline $\begin{array}{l}\text { Canela (Cinnamomum } \\
\text { verum) }\end{array}$ & $\begin{array}{l}\text { Propriedades digestivas, adstringentes, estimulante é muito utilizada } \\
\text { como antiácido natural e em casos de anorexia, prisão de ventre, } \\
\text { tosse, gripe, resfriado, febres e vômitos }\end{array}$ \\
\hline $\begin{array}{l}\text { Espinheira santa (Maytenus } \\
\text { ilicifolia) }\end{array}$ & $\begin{array}{l}\text { Gastrite, úlcera, indigestão, dispepsia. Também é utilizada nas } \\
\text { afecções gástricas como atonia, hiperacidez, úlceras gástricas e } \\
\text { duodenais e gastrite crônica. }\end{array}$ \\
\hline $\begin{array}{l}\text { Camomila } \\
\text { chamomilla) } \quad \text { Matricaria }\end{array}$ & $\begin{array}{l}\text { Antiespasmódica, anti-inflamatória, antisséptica, cicatrizante, } \\
\text { depurativa, emoliente e sudorífica. Estimulante das funções } \\
\text { hepáticas evitando formação de cálculos de vesícula, auxilia na } \\
\text { digestão, evita gastrite e úlcera. }\end{array}$ \\
\hline Hortelã (Mentha) & $\begin{array}{l}\text { Má digestão, diminuir cólicas em geral (intestinais e menstruais), } \\
\text { náuseas e flatulências. }\end{array}$ \\
\hline Boldo (Peumus boldus) & $\begin{array}{l}\text { Estimulante de secreções gástricas, antidispéptico, tratamento de } \\
\text { cálculos biliares, cistite e diurético, diminui acidez e o volume da } \\
\text { secreção do suco gástrico, controle de gastrite, dispepsia, azia, mal- } \\
\text { estar gástrico e ressaca. }\end{array}$ \\
\hline $\begin{array}{l}\text { Alcachofra } \\
\text { scolymus) }\end{array}$ & $\begin{array}{l}\text { Doenças do fígado, regulador da função biliar, estimulante renal e } \\
\text { hiperlipidêmica. }\end{array}$ \\
\hline
\end{tabular}


A carqueja (Baccharis trimera), pertencente à família Asteraceae ou Compositae, é conhecida também como: carquejão, carqueja-amarga, carquesia (espanhol), carque ou baccharis (inglês), calamandrina (italiano) é considerada uma invasora de plantações que se encontram abandonadas, pois se alastram com extrema facilidade. Apresenta na medicina popular ação antirreumática, estomáquica, anti-helmíntica, problemas relacionados ao fígado além de ser considerada boa também para gripe, debilidade física, anemia, anorexia, hanseníase, alguns antigos curandeiros também acreditavam que pudesse auxiliar na impotência masculina e esterilidade feminina e no combate das doenças sexuais (TORRES, 2014).

A espinheira-santa (Maytenus ilicifolia) da família Celestraceae, é nativa da região sul do Brasil, possui denominações como cancorosa, espinheira divina, espinheira santa, cancerosa de sete espinhos entre outros. Sua grande utilidade na medicina alternativa é empregada de longa data nas dores gástricas: gastrite, úlcera, indigestão e dispepsia. Também é utilizada nas afecções gástricas como atonia, hiperacidez, úlceras gástricas e duodenais e gastrite crônica. O chá é indicado no preparo de 1 xícara de água fervente e 1 colher de sobremesa de folhas picadas na quantidade de 1 xícara antes das principais refeições (LORENZI; MATOS, 2008).

A canela (Cinnamommum zeylanicum) da família Lauraceae, possui denominações como: canela-verdadeira, Zimtbaum (alemão), Cannelier de Ceylan (francês), canella (italiano) entre outros. É uma planta originária do Sri Lanka, antigo Ceilão, e foi introduzida no Ocidente a muitíssimo tempo. A canela verdadeira possui óleos essenciais com propriedades antimicrobianas, por este motivo é bastante usada em conservas, compotas, vinhos e licores finos por ser um excelente conservante de alimentos. Possui propriedades digestivas, adstringentes, estimulantes e é muito utilizada como antiácido natural e em casos de anorexia, obstipação, tosse, gripe, resfriado, febres e vômitos (TORRES, 2014).

A camomila (Matricaria recutita), da família Asteraceae, também conhecida como camomila-vulgar, camomila-alemã, camomilha ou camomila-dos-alemães, possui atividade antiespasmódica devida à ação conjunta do óleo essencial e dos flavonóides. Foi comprovada ação antiúlcerativa por efeito gastroprotetor, deve ser feito uso interno para obtenção da ação antiespasmódica intestinal, dispepsias funcionais. Pode ser utilizada por infusão com 2 
colheres de sopa de flores fresca em 1 litro de água fervente. Seu uso deve ser desencorajado em gestantes ou lactantes. Acredita-se que a camomila seja abortiva, e alguns de seus componentes mostraram ter efeitos teratogênicos em vários animais. Utilizar com cautela na hipersensibilidade aos componentes dos óleos voláteis (FETROW; AVILA, 2000).

A hortelã (Mentha) com o tempo foi adotada para muitas áreas como aromaterapia, fitoterapia, a perfumaria, a medicina, a homeopatia e a culinária. É conhecido popularmente como hortelã, no entanto, corresponde a várias espécias, sendo a mais conhecida e utilizada a hortelã-pimenta (Mentha piperita), considera (a matriz de todas as variedades cultivadas. Além dela tem a hortelã-verde (Mentha spicata) e o poejo (Mentha pulegium), sendo todas ter a mesma propriedade. A hortelã é utilizada para o sistema digestório, sendo eficaz ajudar na má digestão para diminuir cólicas em geral (intestinais e menstruais), náuseas e flatulências. Seu preparo pode ser feito de três formas: cocção, infusão e decocção. Porém a infusão é a forma mais comum de preparo. Para o chá é indicado 10g (duas colheres de sopa) da erva seca para um litro de agua fria e ferver de 15 a 20 minutos (LEMOS; LEMOS, 2012).

O boldo nacional (Peumus boldus), da família Lamiaceae é de clima tropical, originária da África. É uma erva perene, de ramos decumbentes a eretos, suas folhas medem aproximadamente, de $12 \mathrm{~cm}$ de comprimento a $8 \mathrm{~cm}$ e largura de margens serradas, pilosas em ambas as faces. Possuem flores andróginas, diclamídeas, pentâmeras, fortemente zigomorfas, agrupadas em longas inflorescências ereta do tipo racemo. Para tratamentos são usadas suas folhas, sendo utilizado como: estimulante de secreções gástricas, o que facilita a digestão, antidispéptico, no tratamento de cálculos biliares, cistite e diurético. Ajuda na diminuição da acidez e o volume da secreção do suco gástrico, podendo ser assim utilizado para o controle de gastrite, dispepsia, azia, mal-estar gástrico e ressaca. Sua forma de uso pode ser por meio de alcoolatura, em que é colocado $20 \mathrm{~g}$ da planta em $100 \mathrm{ml}$ de álcool de cereais a $70 \%$, a ser ingerido de 20 a 40 gotas durante os sintomas ou 3 vezes ao dia; outra forma é o sumo, em que se amassa duas folhas frescas em um copo, completado com água, a ser ingerido de duas a três vezes ao dia. Por fim, pode-se utilizá-lo pela infusão, em que se prepara $10 \mathrm{~g}$ de folha verde em meio litro de água, esfriada posteriormente para uso em banhos quentes antes de dormir em casos de insônia (LAMEIRA, 2008). 
A alcachofra (Cynara scolymus), pertencente à família Asteraceae ou Compositae, com origem a região mediterrâneas da Europa, Ásia e África, é uma planta perene herbácea de 0,9 a 1,5 metros. Apresenta rizoma grosso e escuro, raízes fibrosas, grossas e esbranquiçadas. Tem folhas grandes tendo mais de 1metro de comprimento e profundamente recortadas. A planta tem como função no uso medicinal a moléstias do fígado, regulador da função biliar, estimulante renal e hipolipidêmica. A alcachofra caracteriza-se pelos ácidos fenolíticos presentes em sua composição, em particular a cinarina, a qual ajuda na redução do colesterol. É contraindicada em casos de indivíduos hipersensíveis a família Compositae pois pode causar alergias. No caso de toxicidade deve-se maneirar o uso quando no caso de gestação e amamentação. Sua posologia é indicada em forma de infusão: sendo duas colheres de sopa picada em 1 litro da água, tomar uma xícara de chá 3 vezes ao dia, após as refeições (VIDAL, 2008).

\section{Conclusão}

A partir dos resultados expostos, percebe-se que a produção de fitofármacos (entendidos aqui como moléculas puras obtidas de plantas) é muito importante, principalmente quando se trata de plantas indicadas para tratamento de enfermidades do sistema gastrintestinal. Dessa forma, o uso de plantas medicinais nativas, assim como sobre cultivo e validação destas para sua utilização como medicamentos, é fundamental para o desenvolvimento da ciência. Maiores estudos devem ser conduzidos para vislumbrar os demais efeitos das plantas medicinais apresentadas aqui nesse artigo.

\section{Referências}

BRASIL. Saberes Tradicionais e Biodiversidade no Brasil. Brasília: Ministério do Meio Ambiente; Núcleo de Pesquisas sobre Populações Humanas e Áreas Úmidas Brasileiras (USP), 2001. 
FETROW, C.W.; AVILA, J.R. Manual de Medicina Alternativa: para o profissional. Rio de Janeiro: Guanabara Koogan, p. 423-427, 2000.

LAMEIRA, O.A. Plantas medicinais: do cultivo, manipulação e uso à recomendação popular. EMBRAPA, 2008.

LEMOS, H.P.L.; LEMOS, A.L.A. Hortelã. Diagnóstico e Tratamento, v.17, n.3, p.115-7, 2012.

LORENZI, H.; MATOS, F.J.A. Plantas medicinais no Brasil: nativas e exóticas. 2 ed. Nova Odessa, SP: Instituto Plantarum, 2008.

MOREIRA, R.C.P.; COSTA, L.C.B.; COSTA, R.C.S.; ROCHA, E.M. Abordagem etnobotânica acerca do uso de plantas medicinais na Vila Cachoeira, Ilhéus, Bahia, Brasil. Acta Farmaceutica Bonaerense, v.21, n.3, p.205-211, 2002.

ORGANIZAÇÃO MUNDIAL DE SAÚDE (OMS). Cuidados primários de saúde. Brasília, 1979. 64p. Alma-Ata, 1978.

PINTO, E.P.P.; AMOROZO, M.C.; FURLAN, A. Conhecimento popular sobre plantas medicinais em comunidades rurais de mata atlântica- Itacaré, BA, Brasil. Revista Acta Botanica Brasilica, v.20, n.4, p. 751-762, 2006.

SCHMITZ, D.R.; RIZZON, G. Plantas que curam, 2010.

TORRES, P.G.V. Plantas. Medicinais, Aromáticas\& Condimentares: uma abordagem prática para o dia-a-dia. Porto alegre, 2014.

VIDAL, L. H. I. Atividade de Extratos Aquosos de Plantas sobre Trichophyton rubrum. Londrina: $\quad$ UEL, $2008 . \quad$ Disponível em: <http://www.bibliotecadigital.uel.br/document/?code=vtls000146651> Acesso em: 17 mai 2016.

Como citar este artigo (Formato ABNT):

RIBEIRO, E.I.S.; HASS, Carolina; GASPARETO, Janaina C.I.; ZWIERZYKOWSKI, Thayliyza; SANTOS, Thaliny; MAZUR, Caryna E. O uso de Fitoterápicos como auxílio no tratamento de Enfermidades do Trato Digestório. Id on Line Revista Multidisciplinar e de Psicologia, 2017, vol.11, n.37, p.110-116. ISSN: 1981-1179. 